Original Research

\title{
Topical Ganciclovir Reduces Viral Excretion in Mares With Equine Coital Exanthema
}

\author{
M. Aldana Vissani a, b, c, *, Cecilia Olguin Perglione a , Osvaldo Zabal ${ }^{\text {a, b }}$, Gustavo Alvarez ${ }^{\text {d }}$, \\ Etienne Thiry ${ }^{\text {e }}$, María Barrandeguy ${ }^{\text {a, b }}$, Viviana Parreño ${ }^{\text {a, c }}$ \\ ${ }^{a}$ Instituto de Virología e Innovaciones Tecnológicas (IVIT), Instituto Nacional de Tecnología Agropecuaria (INTA), Buenos Aires, Argentina \\ ${ }^{\mathrm{b}}$ Cátedra de Enfermedades Infecciosas, Escuela de Veterinaria, Universidad del Salvador, Buenos Aires, Argentina \\ ${ }^{c}$ Consejo Nacional de Investigaciones Científicas y Técnicas (CONICET) scientific career, Buenos Aires, Argentina \\ ${ }^{\mathrm{d}}$ Dirección de Remonta y Veterinaria, Ejército Argentino, Buenos Aires, Argentina \\ e Department of Infectious and Parasitic Diseases, Veterinary Virology and Animal Viral Diseases, FARAH Center, Faculty of Veterinary Medicine, University \\ of Liege (B-4000), Liege, Belgium
}

\section{A R T I C L E I N F O}

\section{Article history:}

Received 22 April 2020

Received in revised form 21 June 2020

Accepted 20 July 2020

Available online 24 July 2020

\section{Keywords:}

Equid alphaherpesvirus 3

Coital

Exanthema

Antiviral

Ganciclovir

Topical

\begin{abstract}
A B S T R A C T
Equid alphaherpesvirus 3 (EHV-3) is the etiological agent of equine coital exanthema (ECE). Because no vaccines or antiviral therapies are available, prevention consists of clinical examination of mares and stallions before mating or semen collection and resting from breeding activities when lesions are present. However, this methodology does not identify subclinically infected animals. Ganciclovir is the most potent compound known to reduce EHV-3 replication. This study aimed to evaluate the efficacy of topical ganciclovir application to reduce EHV-3 replication in experimentally infected mares. A pilot study, after a double-blind completely randomized design, was carried out. Twenty mares were randomly divided into five groups (three treated with ganciclovir with different regimen of doses, one treated with a placebo, and one nontreated). Mares were experimentally infected with EHV-3 on day 0. Rectal temperature, clinical signs, and lesions were recorded. Daily perineal and vaginal swabs were evaluated by quantitative polymerase chain reaction for virus detection. The antibody response was assessed by a virus neutralization test in serum samples collected weekly. Mares experimentally infected with EHV-3 and treated with ganciclovir twice a day for 13 days showed reduced levels and duration of viral excretion and less severe lesions. The viral excretion period was reduced from 18 to nine days compared with the untreated groups. We concluded that ganciclovir had an antiviral effect on EHV-3 replication when topically administered in mares showing clinical signs of ECE. Further trials should be performed to optimize the dose of the antiviral for a definitive formulation.
\end{abstract}

() 2020 Published by Elsevier Inc.

\footnotetext{
Aldana Vissani: Contributed to Conceptualization, Methodology, Investigation, Formal analysis, Writing - original draft and Visualization. Cecilia Olguin Perglione: Contributed to Methodology, Investigation. Osvaldo Zabal: Contributed to Resources and Methodology. Gustavo Alvarez: Contributed to Resources and Methodology. Etienne Thiry: Contributed to validation, external Supervision, Writing review \& editing. María Barrandeguy: Contributed to Funding acquisition, conceptualization, supervision, Writing - review \& editing. Viviana Parreño: Contributed to Formal analysis, supervision, Writing - review \& editing.

Animal welfare/ethical statement: All the procedures were approved by the Institutional Committee for Care and Use of Experimental Animals of INTA (CICUAE Resolution 32/2011).

Conflict of interest statement: none.

* Corresponding author at: M. Aldana Vissani, Instituto de Virología e Innovaciones Tecnológicas (IVIT), Instituto Nacional de Tecnología Agropecuaria (INTA), Nicolas Repetto y Los reseros S/N, Hurlingham (1716), Buenos Aires, Argentina.

E-mail address: vissani.aldana@inta.gob.ar (M.A. Vissani).
}

\section{Introduction}

Equid alphaherpesvirus 3 (EHV-3), a member of the subfamily Alphaherpesvirinae and genus Varicellovirus, is the etiological agent of equine coital exanthema (ECE). The ECE is a venereal, highly contagious disease, characterized by the formation of papules, vesicles, pustules, and ulcers on the external genitalia of mares and stallions. Equid alphaherpesvirus 3 is endemic in most equine populations worldwide. The virus is transmitted through direct contact mainly by sexual intercourse, but also by contaminated equipment, and can potentially be transmitted to the ejaculate through penile contact with an artificial vagina or sleeve [1]. After the primary infection, horses remain latently infected with unpredictable periods of reactivation and re-excretion generally 
without any clinical manifestation [1,2]. Virus replication is limited to the stratified epithelium of epidermal tissues of skin, mucocutaneous margins, and mucous membrane. The destruction of the epithelium induced by the lytic infection elicits a vigorous localized inflammatory response that gives rise to the formation of characteristic cutaneous lesions of ECE [3,4]. Infertility and abortion associated with EHV-3 have not been reported [1,5].

The Thoroughbred industry allows only natural mating. The seasonal reproductive activity is principally stimulated by photoperiod, and during the breeding season, the mare cycle length is about 22 days with 5-7 days of estrus [6]. Then, approximately 100 stallions/year, known as 'shuttle' stallions, fulfill a breeding season in both hemispheres in the same calendar year [7].

Countries with major Thoroughbred industries are the United States, Australia, Ireland, and Argentina. Thus, in intensively managed stud operations, heavily scheduled breeding dates are programmed for Thoroughbred stallions.

Taking together the previous information, the main negative consequences of ECE are the temporary disruption of mating activities of affected stallions and mares (for the Thoroughbred industry) and the risk of iatrogenic EHV-3 dissemination and outbreaks of ECE in mares (principally in artificial insemination and embryo transfer facilities) [1]. Because no vaccines or antiviral therapies against EHV-3 are yet available, currently, prevention is based on clinical examination of mares and stallions before mating, which allows segregating those with clinical evidence of ECE. The implemented methodology does not identify subclinically infected animals. As an example, in Argentina, 48\% of mares are seropositive, thus latently infected, and $6 \%$ excrete the virus without clinical signs [8], leading to a high risk of contagion. A pen-site diagnostic tool for the rapid detection of EHV-3 in perineal and vaginal swabs (PVSs) from mares and stallions was described recently and is available for rapid diagnostic in breeding farms [9], although it is not still a common practice.

A possible therapeutic strategy against EHV-3 could be the antiviral chemotherapy used for human herpesviruses, as it would decrease the convalescence time and the excretion of the virus from infected animals, and therefore the risk of transmission [10]. Nucleoside analogs, such as acyclovir, ganciclovir, their prodrugs valaciclovir and valganciclovir, and penciclovir, have been extensively evaluated in vivo against equid herpesvirus 1 but scarcely evaluated against EHV-3 [10-12]. In the case of ganciclovir, the effective concentration $50 \%\left(\mathrm{EC}_{50}\right.$ ) for $\mathrm{EHV}-3$ plaque number has been first determined as $0.16 \mu \mathrm{g} / \mathrm{mL}$ [13] and later confirmed $\left(\mathrm{EC}_{50}\right.$ : $0.18 \mu \mathrm{g} / \mathrm{mL} ; \mathrm{EC}_{100}: 1.25 \mu \mathrm{g} / \mathrm{mL}$ ) and also determined its $\mathrm{EC}_{50}$ and $\mathrm{EC}_{100}$ for plaque size as $0.05 \mu \mathrm{g} / \mathrm{mL}$ and $0.92 \mu \mathrm{g} / \mathrm{mL}$, respectively [14]. Moreover, the efficacy of ganciclovir was compared with acyclovir and cidofovir in vitro and the effectiveness at an optimum concentration was also investigated with different EHV-3 field isolates [14]. These studies demonstrated that ganciclovir is the most potent compound known to reduce EHV-3 replication in vitro [14]. Then, the present study aimed to evaluate the efficacy of the topical application of ganciclovir to reduce EHV-3 replication in experimentally infected mares.

\section{Materials and Methods}

\subsection{Animals}

Twenty EHV-3-seronegative mares between three and four years old were selected from a group of Standardbred mares. These mares were never mated. The seronegativity of these animals was confirmed by performing the EHV-3 seroneutralization test in two consecutive serum samples, with 20-day interval.
All the mares were housed together in a $1,925-\mathrm{m}^{2}$ paddock, without limitations on horse-to-horse contact between groups, with continuous access to water and alfalfa hay and supplemented with $4 \mathrm{~kg}$ of oat grains/mare/day.

All the procedures were approved by the Institutional Committee for Care and Use of Experimental Animals (CICUAE Resolution 32/2011).

\subsection{Virus}

The EHV-3 strain E/9283/07, isolated from perineal lesions in a polo mare during an outbreak of ECE in an embryo transfer facility [2], was plaque-purified three times on an equine dermis cell line (NBL-6, catalog number CCL- 57, ATCC, Manassas, Virginia, USA) and passed twice in the same cell culture. The volume of virus obtained $(140 \mathrm{~mL})$ was titrated by tissue culture infective dose $50 \%$ $\left(\mathrm{TCID}_{50}\right) / \mathrm{ml}$ and by quantitative real-time polymerase chain reaction (qPCR), being the titer $10^{5,33} \mathrm{TCID}_{50} / \mathrm{ml}$, representing $10^{6,22}$ $\mathrm{TCID}_{50} / \mathrm{ml}$ equivalents, respectively. This total volume was then aliquoted in 21 individual tubes of $5 \mathrm{~mL}$ each and kept at $-70^{\circ} \mathrm{C}$ until use, being this the inoculum used for the infection.

\subsection{Ganciclovir}

The concentration of ganciclovir (GCV; Cat. No. G2536; $\geq 99 \%$ purity by HPLC, Merck KGaA, Darmstadt, Germany) for this trial was selected based on previous in vitro analysis against EHV-3 [14]. For the present study, the in vitro concentration $(1.01 \mu \mathrm{g} / \mathrm{mL})$ was increased 100 times for the formulation of the topical cream based on similar studies in humans [15] and considering possible factors that could reduce the action of the drug. Thus, GCV was prepared at $0.01 \%$ by weight $(\mathrm{w} / \mathrm{w})$ using base cream (15\% ethylic alcohol, $1 \%$ white wax, $10 \%$ propylene glycol, $2 \%$ sodium lauryl sulfate, and purified water) as the vehicle. Briefly, $100 \mathrm{mg}$ of GCV was resuspended in $50 \mathrm{~mL}$ of Roswell Park Memorial Institute 1640 (RPMI$1640)_{\text {medium }}^{2}$ (51.7 g), which was added to $948.3 \mathrm{~g}$ of base cream (final weight: $1000 \mathrm{~g}$ ). The GCV $0.01 \% \mathrm{w} / \mathrm{w}$ cream was then homogenized manually, and the uniformity of the mixing was visualized by the red dye phenol included in the RPMI-1640 medium. Base cream without GCV was used as a placebo.

\subsection{Experimental Design}

A pilot study was conducted in mares experimentally infected with EHV-3, after a double-blind completely randomized design to compare, in the same field trial, the efficacy of the topical administration of GCV $0.01 \% \mathrm{w} / \mathrm{w}$ as preventive or therapeutic treatment.

The 20 mares were identified in their left back by writing the numbers 1 to 20 using ad hoc crayons and then randomly distributed in five treatment groups, with four mares each. As shown in Table 1, three of the groups were treated with GCV 0.01\% w/w (two preventive and one therapeutic treatment), one was treated with a placebo, and the other one was not treated (the control group). Considering welfare recommendations, the number of treatment groups $(n=5)$ was prioritized to the number of experimental units per treatment $(n=4)$ to obtain data regarding preventive and therapeutic applications of the antiviral in the same field conditions.

For the preventive treatments, $5 \mathrm{~g}$ of GCV $0.01 \% \mathrm{w} / \mathrm{w}$ was applied to the vulva and the perineal area, either only once at 4 hours postinfection (hpi) (group $\mathrm{P}_{4}$ ) or twice at 4 and 24 hpi (group $\mathrm{P}_{4 / 24}$ ). These treatments aimed to simulate infected mares shedding virus without clinical lesions of ECE. If effective, this preventive treatment would prevent the transmission to the stallion during mating. 
Table 1

Experimental design for the evaluation of the efficacy of GCV $0.01 \% \mathrm{w} / \mathrm{w}$ on experimentally infected mares.

\begin{tabular}{|c|c|c|c|}
\hline \multirow[t]{2}{*}{ Group } & \multirow[t]{2}{*}{ Infection } & \multicolumn{2}{|l|}{ Treatment } \\
\hline & & Application & Product \\
\hline Control (C) & Yes & No & None \\
\hline Preventive $4 \mathrm{~h}(\mathrm{P} 4)$ & Yes & One application at $4 \mathrm{hpi}$ (day 0 ) & GCV $0.01 \% \mathrm{w} / \mathrm{w}$ \\
\hline Preventive $4 / 24 h(\mathrm{P} 4 / 24)$ & Yes & Two applications at 4 and 24 hpi (days 0 and 1 ) & GCV $0.01 \% \mathrm{w} / \mathrm{w}$ \\
\hline Therapeutic with GCV (TGCV) & Yes & Twice a day during clinical equine coital exanthema & GCV $0.01 \% \mathrm{w} / \mathrm{w}$ \\
\hline Therapeutic with a placebo (TP) & Yes & Twice a day during clinical equine coital exanthema & Placebo \\
\hline
\end{tabular}

Abbreviations: hpi, hours postinfection; GCV, ganciclovir; w/w, by weight.

For the therapeutic approach, $5 \mathrm{~g}$ of GCV $0.01 \% \mathrm{w} / \mathrm{w}$ was applied to the vulva and the perineal area, specifically to the lesions, also in those observed out of the inoculation area, twice daily because lesions were evident (day 6 postinfection) and during the entire period of clinical evidence of ECE, which resulted in 13 days (group $\left.T_{G C V}\right)$. The placebo group $\left(T_{P}\right)$ received the same regimen of doses as group $\mathrm{T}_{\mathrm{GCV}}$ but of a placebo cream instead of the formulation containing GCV. Finally, as mentioned above, the control group (C) consisted of four nontreated mares.

Before the application of the inoculum (day 0), PVSs and serum samples were taken from each mare to confirm their seronegative status and the absence of virus shedding. All mares were topically infected by using a sterile swab moistened with $5 \mathrm{~mL}$ of the EHV-3 inoculum on the vulva and perineal skin surrounding the vulvar labia, as previously reported [16]. To confirm that the virus given to each mare suffered no inactivation through the inoculation process, the trace of inoculum recovered after the challenge was saved for virus back titration by $\mathrm{TCID}_{50} / \mathrm{ml}$.

\subsection{Clinical Monitoring}

Mares were clinically examined (observation of the genital and perineal skin and mucosa) and their rectal temperature was determined by a trained veterinarian blinded to the treatment group. This was carried out every morning from day 0 to day 36 postinfection (dpi), before the collection of samples and administration of the treatments, which was carried out by another veterinarian.

Genital and perineal skin and mucosa were thoroughly observed and ECE lesions were evaluated using a scoring system [16] shown in Table 2. For each of the possible clinical signs (tumefaction, discharge, pain, lesions, and others), a score was attributed depending on the severity. During the clinical evaluation, each clinical sign was evaluated and a score was given. Finally, the daily score of an individual mare was defined as the sum of the scores of all clinical signs and lesions observed that day. The mean and standard deviation of the daily clinical score and temperature recorded for each group were calculated and the area under the curve (AUC) of the clinical score of each mare and the mean for each group were calculated at the end of the experiment (0-36 dpi).

The rectal temperature of each mare was assessed using a rectal thermometer, and the environmental temperature was recorded using a digital thermometer (SCT2, Schwyz, Buenos Aires, Argentina).

\subsection{Sample Collection and Storage}

Sampling was performed daily in the morning from 0 to $36 \mathrm{dpi}$ after clinical monitoring and before the administration of treatments when required. Perineal and vaginal swabs for virus detection were collected daily in $5 \mathrm{~mL}$ of viral transport media (D-MEM, E-MEM, 10\% fetal calf serum, 1\% streptomycin-gentamycin-penicillin, and $0.2 \%$ fungizone, Thermo Fisher Scientific Inc., Waltham, MA, USA) by roughly rubbing the perineal/ vaginal area with a sterile swab. Immediately on arrival at the laboratory, swabs were split in five aliquots of $1 \mathrm{~mL}$ each and stored at $-70^{\circ} \mathrm{C}$ until use. A sample of $200 \mu \mathrm{L}$ was directly subjected to DNA extraction.

Serum samples were collected once a week to evaluate the antibody response against EHV-3 through a viral neutralization test, as previously reported [16]. Responses of neutralizing antibodies in mares were expressed as the log transformation of the reciprocal of the highest serum dilution showing protection to infection when mixed with $100 \mathrm{TCID}_{50} / \mathrm{ml}$ of the virus.

\subsection{Quantitative Real-Time PCR ( $q P C R$ )}

Viral DNA was extracted from PVSs by using the High Pure PCR Template Preparation Kit (Roche Diagnostic Corporation, Indiana, USA, catalog number 11796828001), in accordance with the manufacturer's instructions. To detect and quantify EHV-3, a qPCR targeting a region of the EHV-3 $g G$ gene was performed [17]. Quantification of EHV-3 in PVSs was calculated by generating a standard curve with log dilutions of the reference strain containing $10^{5.36} \mathrm{TCID}_{50} / \mathrm{ml}$. In accordance with the qPCR diagnostic validation (data not shown), the cutoff was set in a cycle threshold value of

Table 2

Clinical scoring system used to quantify the severity of ECE-associated lesions.

\begin{tabular}{|c|c|c|c|c|c|}
\hline Score & 0 & 1 & 2 & 3 & 4 \\
\hline Tumefaction & None & Present & - & - & - \\
\hline Discharge & None & Serous & Mucous & Purulent & - \\
\hline Pain & None & Present & - & - & - \\
\hline \multicolumn{6}{|l|}{ Lesion } \\
\hline Type & None & Papule & Vesicle & Pustule & Erosion/ulcers \\
\hline Size & None & Small (up to $1 \mathrm{~cm}$ ) & Large (more than $1 \mathrm{~cm}$ ) & - & - \\
\hline Number & None & Up to 4 & More than 4 & - & - \\
\hline Extension & None & In the inoculation area & Out of the inoculation area & - & - \\
\hline Others & None & Secondary bacterial infection/myiasis & - & - & - \\
\hline
\end{tabular}

Abbreviation: ECE, equine coital exanthema.

"-": no option of severity of lesions is available. 
31.04 (corresponding to $10^{2.93} \mathrm{TCID}_{50} / \mathrm{ml}$ equivalents) with $100 \%$ sensitivity and $96.6 \%$ specificity.

\subsection{Virus Isolation}

To establish the last day of excretion of infectious virus (last day of potential contagion), we attempted to isolate the virus from swabs that had a qPCR positive result after the treatment. Perineal and vaginal swabs were centrifuged at 14,000 rpm for 10 minutes to remove organic (urine, feces, cellular, and hair detritus) and cream contamination, and the supernatant was then inoculated in duplicate onto monolayers of NBL-6 cells in 12-well tissue culture plates. After 2 hours at $37^{\circ} \mathrm{C}$, the inoculated cell monolayers were washed three times with D-MEM, and then $2 \mathrm{~mL}$ of maintenance media (D-MEM, E-MEM, 5\% fetal calf serum) were added. A negative control, inoculated with viral transport media, was included in each plate. The presence $(+)$ /absence $(-)$ of the cytopathic effect was recorded by microscopic examination for seven consecutive days.

\subsection{Data Analysis}

As this experiment was conducted as a pilot study, one of our main objectives was to have the first result of variance and the effect size of each variable under study by using this reduced number of mares per group. Thus, a power calculation was not performed a priori but thereafter, starting with the power obtained using this minimum number of animals and studying how the power of each variable will improve by increasing the number of animals per group.

For the inoculum titer from each mare, the mean virus titer in terms of the $\log _{10}$-transformed $\mathrm{TCID}_{50} / \mathrm{ml}$ of each group was calculated. Normality and homoscedasticity assumptions were checked and the mean virus titer among groups was compared by one-way analysis of variance (ANOVA).

The severity of the disease per group was analyzed and compared in terms of the following variables: days to onset, duration, peak day, and peak of clinical signs. In addition, a global variable to study disease severity was calculated as the AUC [18] of the clinical scores recorded for each mare from 0 to $36 \mathrm{dpi}$. All these parameters were analyzed using a general linear mixed model (GLMM) considering the treatment group as a fixed factor and the mares nested within the groups as a random variable. Heteroscedasticity detected among groups was modeled applying a varldent structure to the variance-covariance matrix. The normal distribution of the residuals of each model was checked by the Shapiro-Wilks test. Differences between means were assessed by Fisher's least significant difference (LSD) for multiple pairwise comparisons, and $P$-values were corrected by the Bonferroni method.

Virus infection was analyzed and compared in terms of days to onset, duration, peak day, peak value, and AUC of virus shedding. Only the variable duration of virus shedding was analyzed using a GLMM as previously described. The other variables that did not meet the normality and homoscedasticity assumptions were evaluated and compared between groups by the Kruskal-Wallis nonparametric rank-sum test.

The power of the statistical analysis was evaluated using the $\mathrm{R}$ pwr package [19].

The percentage of mares shedding infectious virus in the different groups was calculated at selected time points $(8,12,16$, and $20 \mathrm{dpi}$ ). The reduced number of experimental units did not allow statistical analysis.

The statistical analysis of the antibody response was conducted using a GLMM considering the treatment group and the time as fixed factors and the mares as a random variable. The matrix of variance-covariance was modeled assuming the autoregressive effect of testing the same animal through time (AR01) and the heterogeneity of variance at different time points (varIdent). In all cases, significance was established at $P<.05$, and the analyses were performed with commercial software (InfoStat with connection to R, version 2017, Grupo InfoStat, Córdoba, Argentina. URL: http:// www.infostat.com.ar).

\section{Results}

\subsection{Inoculum}

Before the experimental administration of the inoculum, mares were negative for EHV-3 excretion in PVS samples and negative for antibodies to EHV-3 in serum by the seroneutralization test. The mean virus titer of the inoculum of each group was calculated, and because the normality and homoscedasticity assumptions were met, they were compared by one-way ANOVA. There was no significant difference in the dose of EHV-3 received by all mares $(P=.2)$, indicating that they were challenged with the same amount of virus (Table 3 ).

\subsection{Major Clinical Findings}

After virus inoculation, typical ECE lesions (papules, vesicles, pustules, and ulcers) were observed in all the inoculated mares from 1 to 3 dpi (Fig. 1). Tumefaction, vulvar discharge, and pain were also observed in all the mares with varying intensity. Raw data of clinical scores applied to EHV-3-induced lesions for each mare during the experience are shown in Table 4. One of the mares (mare 7) developed lesions out of the inoculated area in the base of the tail, and another one (mare 6) developed myiasis (Fig. 1). None of the mares showed hyperthermia or systemic clinical signs (i.e., no apathy, lethargy, or anorexia) during the experimental study.

After the resolution of clinical disease and virus shedding in all the mares, two of them, mares 5 and 15 , from the $T_{G C V}$ and $T_{P}$ groups, respectively, showed viral excretion of EHV-3 without clinical evidence of ECE lesions, with high individual values of $\mathrm{TCID}_{50} / \mathrm{ml}$ equivalents measured by qPCR. Infectious virus was also isolated, at $36 \mathrm{dpi}$ for mare $5\left(\mathrm{~T}_{\mathrm{GCV}}\right)$ and at 23 and $36 \mathrm{dpi}$ for mare 15 $\left(\mathrm{T}_{\mathrm{P}}\right)$.

\subsection{Experimental Model}

The analysis of the data in terms of duration of clinical signs, the peak of clinical score, day of peak value, and the AUC of clinical scores for each mare and the mean for each group is shown in Table 3.

Virus shedding was detected by qPCR in all mares. The amount of virus shedding determined for each mare was expressed as $\log _{10}$ of EHV-3 $\mathrm{TCID}_{50} / \mathrm{ml}$ equivalents for selected critical time points (to define the resolution of the infection during the trial), together with the mean and standard deviation for each of the groups. These data were analyzed in terms of the duration of virus shedding, the peak of virus shedding, the day corresponding to the peak value, and the AUC of virus shedding for each mare and the mean for each group. The presence/absence of infectious viruses was assessed by virus isolation in cell culture in PVS positive by qPCR after treatments, at the selected time points $(8,12,16$, and $20 \mathrm{dpi})$. Table 3 summarized the results on clinical signs, virus shedding, and infectious viruses. 
Table 3

Summary of the variables analyzed for clinical signs and virus shedding in mares experimentally challenged with EHV-3 and treated with GCV $0.01 \% \mathrm{w} / \mathrm{w}$.

\begin{tabular}{|c|c|c|c|c|c|c|c|c|c|c|c|c|c|c|c|c|}
\hline \multirow{2}{*}{$\begin{array}{l}\text { Mares } \\
\text { Group }\end{array}$} & \multirow[b]{2}{*}{ ID } & \multirow{2}{*}{$\begin{array}{l}\text { Virus } \\
\text { Inoculum } \\
\text { (Log10 } \\
\text { TCID50/ml) }\end{array}$} & \multicolumn{5}{|c|}{ Clinical Signs } & \multicolumn{5}{|c|}{ Virus Shedding } & \multicolumn{4}{|c|}{ Infectious Virus $^{\mathrm{a}}$} \\
\hline & & & $\begin{array}{l}\text { Day to } \\
\text { onset }\end{array}$ & $\begin{array}{l}\begin{array}{l}\text { Duration } \\
\text { (days) }\end{array} \\
\end{array}$ & $\begin{array}{l}\text { Day of } \\
\text { peak score }\end{array}$ & $\begin{array}{l}\text { Peak } \\
\text { score }\end{array}$ & $\begin{array}{l}\text { AUC 0-36 } \\
\text { dpi }\end{array}$ & $\begin{array}{l}\text { Day } \\
\text { of } \\
\text { onset }\end{array}$ & $\begin{array}{l}\begin{array}{l}\text { Duration } \\
\text { (days) }\end{array} \\
\end{array}$ & $\begin{array}{l}\text { Day of } \\
\text { peak virus } \\
\text { shedding }\end{array}$ & $\begin{array}{l}\text { Peak of virus } \\
\text { shedding } \\
\text { (Log10 } \\
\text { TCID50/ml } \\
\text { equivalents) }\end{array}$ & $\begin{array}{l}\text { Log AUC } \\
0-36 \mathrm{dpi}\end{array}$ & $8 \mathrm{dpi}$ & $\begin{array}{l}12 \\
\mathrm{dpi}\end{array}$ & $\begin{array}{l}16 \\
\text { dpi }\end{array}$ & $\begin{array}{l}20 \\
\text { dpi }\end{array}$ \\
\hline \multirow[t]{5}{*}{ Control (C) } & 3 & 5.95 & 1 & 19 & 10 & 14 & 167.5 & 1 & 20 & 12 & 7.51 & 7.78 & + & + & - & - \\
\hline & 9 & 5.96 & 1 & 20 & 12 & 13 & 205 & 1 & 20 & 12 & 7.38 & 7.45 & + & + & + & - \\
\hline & 14 & 5.74 & 1 & 18 & 10 & 11 & 120 & 1 & 12 & 4 & 6.45 & 7.00 & + & + & - & - \\
\hline & 18 & 6.13 & 3 & 16 & 8 & 12 & 135 & 1 & 21 & 12 & 7.00 & 7.32 & + & + & + & + \\
\hline & Mean & $5.95 \mathrm{~A}$ & 1.50 & $18.25 \mathrm{~A}$ & $10 \mathrm{~B}$ & $12.5 \mathrm{~A}$ & $156.88 \mathrm{~A}$ & 1 & $18.25 \mathrm{~A}$ & $10 \mathrm{~A}$ & $7.08 \mathrm{~A}$ & $7.39 \mathrm{~A}$ & $100 \%$ & $100 \%$ & $50 \%$ & $25 \%$ \\
\hline \multirow{5}{*}{$\begin{array}{r}\text { Preventive } \\
4 \mathrm{~h}(\mathrm{P} 4)\end{array}$} & 2 & 6.16 & 1 & 18 & 8 & 8 & 98.5 & 1 & 12 & 4 & 5.86 & 6.58 & + & + & - & - \\
\hline & 10 & 6.11 & 1 & 17 & 7 & 5 & 74 & 4 & 9 & 8 & 2.64 & 3.37 & + & + & - & - \\
\hline & 11 & 6.08 & 2 & 17 & 14 & 10 & 130 & 1 & 16 & 12 & 7.17 & 7.08 & + & + & - & - \\
\hline & 20 & 5.98 & 2 & 17 & 8 & 12 & 117 & 1 & 12 & 12 & 6.69 & 7.39 & + & + & - & - \\
\hline & Mean & $6.09 \mathrm{~A}$ & 1.5 & $17.25 \mathrm{~A}$ & $9.25 \mathrm{BC}$ & $8.75 \mathrm{~A}$ & $104.88 \mathrm{~A}$ & 1.75 & $12.25 \mathrm{BC}$ & $9 \mathrm{~A}$ & $5.59 \mathrm{~A}$ & $6.10 \mathrm{~A}$ & $100 \%$ & $100 \%$ & $0 \%$ & $0 \%$ \\
\hline \multirow{5}{*}{$\begin{array}{l}\text { Preventive } \\
\qquad 4 / 24 \text { h (P4/24) }\end{array}$} & 6 & 6.00 & 3 & 21 & 15 & 15 & 216.5 & 1 & 20 & 8 & 6.52 & 7.28 & + & + & + & - \\
\hline & 8 & 5.96 & 1 & 23 & 16 & 8 & 144.5 & 1 & 23 & 12 & 7.75 & 6.27 & + & + & + & + \\
\hline & 17 & 5.98 & 2 & 17 & 12 & 10 & 112 & 1 & 16 & 12 & 5.79 & 7.39 & + & + & - & - \\
\hline & 19 & 5.92 & 1 & 17 & 12 & 7 & 98.5 & 1 & 16 & 12 & 6.85 & 6.64 & + & + & + & - \\
\hline & Mean & $5.97 \mathrm{~A}$ & 1.75 & $19.50 \mathrm{~A}$ & $13.75 \mathrm{~A}$ & $10 \mathrm{~A}$ & $142.88 \mathrm{~A}$ & 1 & $18.75 \mathrm{~A}$ & $11 \mathrm{~A}$ & $6.73 \mathrm{~A}$ & $6.90 \mathrm{~A}$ & $100 \%$ & $100 \%$ & $75 \%$ & $25 \%$ \\
\hline \multirow{5}{*}{$\begin{array}{c}\text { Therapeutic } \\
\text { with GCV } \\
\text { (TGCV) }\end{array}$} & 5 & 6.04 & 1 & 18 & 6 & 13 & 130.5 & 1 & 8 & 4 & 5.52 & 7.37 & + & - & - & - \\
\hline & 7 & 6.01 & 1 & 16 & 6 & 9 & 87.5 & 1 & 8 & 2 & 5.56 & 7.21 & + & - & - & - \\
\hline & 12 & 6.07 & 1 & 18 & 9 & 15 & 166 & 1 & 12 & 4 & 6.82 & 6.34 & + & - & - & - \\
\hline & 13 & 6.07 & 1 & 18 & 8 & 13 & 142.5 & 1 & 8 & 4 & 6.64 & 6.38 & + & - & - & - \\
\hline & Mean & $6.05 \mathrm{~A}$ & 1 & $17.50 \mathrm{~A}$ & $7.25 \mathrm{C}$ & $12.50 \mathrm{~A}$ & $131.63 \mathrm{~A}$ & 1 & $9 \mathrm{C}$ & $3.50 \mathrm{~B}$ & $6.16 \mathrm{~A}$ & $6.83 \mathrm{~A}$ & $100 \%$ & $0 \%$ & $0 \%$ & $0 \%$ \\
\hline \multirow{5}{*}{$\begin{array}{l}\text { Therapeutic with a } \\
\text { placebo (TP) }\end{array}$} & 1 & 6.05 & 2 & 17 & 8 & 13 & 147 & 1 & 12 & 12 & 7.56 & 7.31 & + & + & + & - \\
\hline & 4 & 6.07 & 2 & 17 & 6 & 9 & 128.5 & 1 & 16 & 2 & 6.12 & 6.91 & + & + & - & - \\
\hline & 15 & 5.97 & 1 & 19 & 9 & 13 & 142 & 1 & 21 & 12 & 6.15 & 7.07 & + & + & - & - \\
\hline & 16 & 5.99 & 2 & 17 & 9 & 15 & 163 & 1 & 12 & 12 & 6.20 & 7.44 & + & + & - & - \\
\hline & Mean & $6.02 \mathrm{~A}$ & 1.75 & $17.50 \mathrm{~A}$ & $8.00 \mathrm{BC}$ & $12.50 \mathrm{~A}$ & $145.13 \mathrm{~A}$ & 1 & $15.25 \mathrm{AB}$ & $9.50 \mathrm{~A}$ & $6.51 \mathrm{~A}$ & $7.18 \mathrm{~A}$ & $100 \%$ & $100 \%$ & $25 \%$ & $0 \%$ \\
\hline \multirow{3}{*}{$\begin{array}{l}\text { Statistical analysis } \\
\text { Normality }\end{array}$} & & & & & & & & & & & & & & & & \\
\hline & & $\begin{array}{l}\text { Wresiduals } \\
=0.94\end{array}$ & na & $\begin{array}{l}\text { Wresiduals } \\
=0.94\end{array}$ & $\begin{array}{l}\text { Wresiduals } \\
=0.91\end{array}$ & $\begin{array}{l}\text { Wresiduals } \\
=0.93\end{array}$ & $\begin{array}{l}\text { Wresiduals } \\
=0.94\end{array}$ & na & $\begin{array}{l}\text { Wresiduals } \\
=0.98\end{array}$ & $\begin{array}{l}\text { Wresiduals } \\
=0.82\end{array}$ & $\begin{array}{l}\text { Wresiduals } \\
=0.88\end{array}$ & $\mathrm{~W}=0.69$ & na & na & na & na \\
\hline & & $P=.5$ & & $P=.5$ & $P=.1$ & $P=.4$ & $P=.5$ & & $P=.9$ & $P=.001$ & $P=.05$ & $P=.0001$ & & & & \\
\hline Homoscedasticity & & $P=.3$ & & na & na & na & na & & na & & & & & & & \\
\hline $\begin{array}{l}\text { Type of statistical } \\
\text { analysis }\end{array}$ & & $\begin{array}{l}\text { One-way } \\
\text { ANOVA }\end{array}$ & na & GLMM & GLMM & GLMM & GLMM & na & GLMM & $\begin{array}{l}\text { Kruskal- } \\
\text { Wallis }\end{array}$ & $\begin{array}{l}\text { Kruskal- } \\
\text { Wallis }\end{array}$ & $\begin{array}{l}\text { Kruskal- } \\
\text { Wallis }\end{array}$ & na & & & \\
\hline conducted & & $P=.2$ & & $P=.5$ & $\begin{array}{l}\boldsymbol{P}=\mathbf{. 0 0 2} \\
\text { LSD Fisher- } \\
\text { Bonferroni }\end{array}$ & $P=.2$ & $P=.09$ & & $\begin{array}{l}\boldsymbol{P}=\mathbf{. 0 0 8} \\
\text { LSD Fisher- } \\
\text { Bonferroni }\end{array}$ & $P=.1$ & $P=.4$ & $P=.4$ & & & & \\
\hline
\end{tabular}

Abbreviations: na, not applicable; GLMM, general linear mixed model (the fixed factor group-random factor mares nested in groups-heteroscedasticity: varldent); AUC, area under the curve; dpi, days postinfection; LSD, least significant difference.

Bolded $P$ values represents significant difference in the statistical analysis.

${ }^{a}$ Infectious virus: perineal vaginal swabs showing cytopathic effect in cell culture: presence (+)/absence $(-)$. 


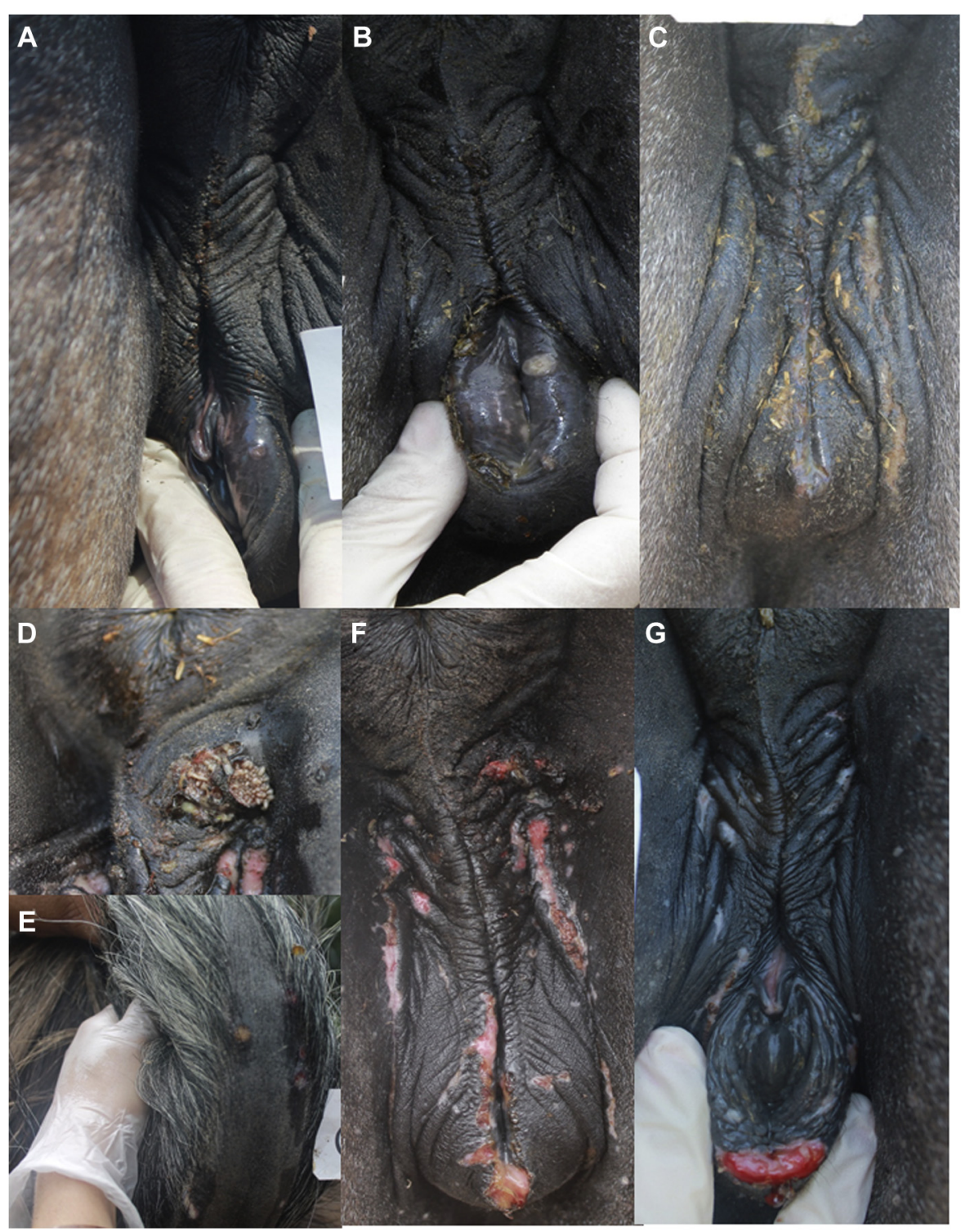

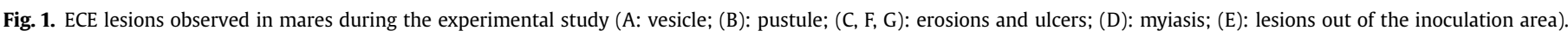

\subsection{Control Groups ( $C$ and $T_{P}$ Groups)}

Regarding control groups, the duration of clinical disease measured in days was 18.25 and 17.50 for groups $C$ and $T_{P}$, respectively. The peak score for both groups was at 12.5 , but the day of the peak score was 10 for group $C$ and 8 for group $T_{P}$.

Regarding virus shedding, the duration in days was 18.25 and 15.25 days for groups $C$ and $T_{p}$, respectively, and the peak of virus shedding and the day of the peak were similar for both groups.

For the detection of the infectious virus, all the mares of both control groups were shedding the infectious virus on $12 \mathrm{dpi}$ (Table 3).

\subsection{Efficacy of GCV as Preventive Treatment ( $P_{4}$ and $P_{4 / 24}$ Groups)}

The preventive treatments with GCV caused no reduction in the number of days with clinical signs (GLMM, $P=.5$ ). However, the mares of group $\mathrm{P}_{4 / 24}$ (treated twice at 4 and 24 hours after challenge) reached the peak of clinical signs at $13.75 \mathrm{dpi}$, almost four days later than the mares of the control group (10 dpi). This represented a significant delay compared with the peak recorded in the rest of the groups, especially the mares of group $\mathrm{P}_{4}$, (treated with only one application), which developed the peak at $9.25 \mathrm{dpi}$ (GLMM LSD Fisher-Bonferroni, $P=.002$ ). On the other hand, the preventive group treated at $4 \mathrm{hpi}$ showed the lowest peak score and lowest total disease severity measured in terms of the mean AUC of clinical scores from 0 to $36 \mathrm{dpi}$ (GLMM, $P=.2$ and $P=.09$, respectively; Table 3 ).

The total amount of virus shed by the mares in the preventive treatment groups showed no significant differences (Kruskal-Wallis nonparametric rank-sum test, $P=.4$ ) when evaluated using the $\log _{10}$-transformed AUC. Mares from group $\mathrm{P}_{4}$ showed reduced virus shedding in more than one $\log _{10}$ compared with the control group; however, this effect was due to the minimal virus shedding observed in mare number 10 .

In contrast, the statistical analysis using a GLMM on the number of days of virus shedding showed significant differences $(P=.008)$ among groups. The mares of the control group shed virus for 18.25 days, similar to those in group $\mathrm{P}_{4 / 24}$ (18.75), whereas the mares of group $\mathrm{P}_{4}$ showed a significant reduction in the number of days of virus shedding (12.2 days). 
Table 4

Raw data of clinical scores applied to EHV-3-induced lesions observed in the mares during the experimental trial.

\begin{tabular}{|c|c|c|c|c|c|c|c|c|c|c|c|c|c|c|c|c|c|c|c|c|c|c|c|c|c|c|c|c|c|c|c|c|c|c|c|c|c|}
\hline \multirow[b]{2}{*}{ Mares } & \multicolumn{37}{|c|}{ Days post-infection } \\
\hline & 0 & 1 & 2 & 3 & 4 & 5 & 6 & 7 & 8 & 9 & 10 & 11 & 12 & 13 & 14 & 15 & 16 & 17 & 18 & 19 & 20 & 21 & 22 & 23 & 24 & 25 & 26 & 27 & 28 & 29 & 30 & 31 & 32 & 33 & 34 & 35 & 36 \\
\hline \multicolumn{38}{|c|}{ Group C } \\
\hline 3 & 0 & 5 & 5 & 7 & 9 & 12 & 12 & 13 & 13 & 13 & 14 & 13 & 12 & 12 & 8 & 8 & 8 & 7 & 5 & 2 & 0 & 0 & 0 & 0 & 0 & 0 & 0 & 0 & 0 & 0 & 0 & 0 & 0 & 0 & 0 & 0 & 0 \\
\hline 9 & 0 & 4 & 5 & 6 & 8 & 10 & 12 & 12 & 12 & 12 & 12 & 12 & 13 & 12 & 10 & 13 & 13 & 10 & 6 & 5 & 5 & 0 & 0 & 0 & 0 & 0 & 0 & 0 & 0 & 0 & 0 & 0 & 0 & 0 & 0 & 0 & 0 \\
\hline 14 & 0 & 1 & 4 & 6 & 7 & 8 & 8 & 8 & 8 & 8 & 11 & 9 & 9 & 6 & 6 & 6 & 6 & 6 & 5 & 0 & 0 & 0 & 0 & 0 & 0 & 0 & 0 & 0 & 0 & 0 & 0 & 0 & 0 & 0 & 0 & 0 & 0 \\
\hline 18 & 0 & 0 & 0 & 5 & 5 & 6 & 9 & 9 & 12 & 12 & 11 & 11 & 11 & 7 & 7 & 7 & 7 & 6 & 5 & 0 & 0 & 0 & 0 & 0 & 0 & 0 & 0 & 0 & 0 & 0 & 0 & 0 & 0 & 0 & 0 & 0 & 0 \\
\hline \multicolumn{38}{|c|}{ Group $\mathrm{P}_{4}$} \\
\hline 2 & 0 & 4 & 5 & 5 & 5 & 6 & 6 & 6 & 8 & 8 & 6 & 6 & 6 & 6 & 6 & 6 & 6 & 5 & 5 & 0 & 0 & 0 & 0 & 0 & 0 & 0 & 0 & 0 & 0 & 0 & 0 & 0 & 0 & 0 & 0 & 0 & 0 \\
\hline 10 & 0 & 4 & 4 & 4 & 4 & 4 & 5 & 5 & 5 & 5 & 4 & 4 & 4 & 4 & 4 & 4 & 4 & 4 & 0 & 0 & 0 & 0 & 0 & 0 & 0 & 0 & 0 & 0 & 0 & 0 & 0 & 0 & 0 & 0 & 0 & 0 & 0 \\
\hline 11 & 0 & 0 & 4 & 5 & 8 & 8 & 9 & 9 & 9 & 9 & 9 & 9 & 9 & 9 & 10 & 8 & 8 & 7 & 6 & 0 & 0 & 0 & 0 & 0 & 0 & 0 & 0 & 0 & 0 & 0 & 0 & 0 & 0 & 0 & 0 & 0 & 0 \\
\hline 20 & 0 & 0 & 4 & 5 & 5 & 6 & 9 & 10 & 12 & 12 & 8 & 8 & 7 & 7 & 7 & 5 & 5 & 5 & 5 & 0 & 0 & 0 & 0 & 0 & 0 & 0 & 0 & 0 & 0 & 0 & 0 & 0 & 0 & 0 & 0 & 0 & 0 \\
\hline \multicolumn{38}{|c|}{ Group $\mathrm{P}_{4 / 24}$} \\
\hline 6 & 0 & 0 & 0 & 5 & 5 & 7 & 9 & 14 & 14 & 14 & 13 & 13 & 13 & 14 & 14 & 15 & 15 & 10 & 6 & 6 & 5 & 5 & 4 & 4 & 0 & 0 & 0 & 0 & 0 & 0 & 0 & 0 & 0 & 0 & 0 & 0 & 0 \\
\hline 8 & 0 & 5 & 5 & 5 & 6 & 6 & 7 & 7 & 7 & 7 & 7 & 7 & 7 & 7 & 7 & 7 & 8 & 7 & 6 & 6 & 4 & 4 & 4 & 4 & 0 & 0 & 0 & 0 & 0 & 0 & 0 & 0 & 0 & 0 & 0 & 0 & 0 \\
\hline 17 & 0 & 0 & 4 & 4 & 6 & 6 & 6 & 6 & 7 & 7 & 8 & 9 & 10 & 6 & 6 & 6 & 5 & 5 & 5 & 0 & 0 & 0 & 0 & 0 & 0 & 0 & 0 & 0 & 0 & 0 & 0 & 0 & 0 & 0 & 0 & 0 & 0 \\
\hline 19 & 0 & 4 & 5 & 5 & 5 & 5 & 6 & 6 & 6 & 6 & 6 & 6 & 7 & 6 & 6 & 6 & 5 & 4 & 0 & 0 & 0 & 0 & 0 & 0 & 0 & 0 & 0 & 0 & 0 & 0 & 0 & 0 & 0 & 0 & 0 & 0 & 0 \\
\hline \multicolumn{38}{|c|}{ Group $\mathrm{T}_{\mathrm{GCV}}$} \\
\hline 5 & 0 & 4 & 5 & 6 & 9 & 10 & 13 & 11 & 11 & 7 & 7 & 6 & 6 & 6 & 6 & 6 & 6 & 5 & 5 & 0 & 0 & 0 & 0 & 0 & 0 & 0 & 0 & 0 & 0 & 0 & 0 & 0 & 0 & 0 & 0 & 0 & 0 \\
\hline 7 & 0 & 4 & 5 & 6 & 8 & 8 & 9 & 8 & 5 & 5 & 5 & 5 & 4 & 1 & 1 & 1 & 1 & 0 & 0 & 0 & 0 & 0 & 0 & 0 & 0 & 0 & 0 & 0 & 0 & 0 & 0 & 0 & 0 & 0 & 0 & 0 & 0 \\
\hline 12 & 0 & 1 & 4 & 6 & 9 & 12 & 12 & 13 & 14 & 15 & 10 & 10 & 10 & 9 & 9 & 9 & 9 & 8 & 7 & 0 & 0 & 0 & 0 & 0 & 0 & 0 & 0 & 0 & 0 & 0 & 0 & 0 & 0 & 0 & 0 & 0 & 0 \\
\hline 13 & 0 & 4 & 5 & 6 & 9 & 9 & 12 & 12 & 13 & 12 & 7 & 7 & 7 & 7 & 7 & 6 & 6 & 5 & 4 & 0 & 0 & 0 & 0 & 0 & 0 & 0 & 0 & 0 & 0 & 0 & 0 & 0 & 0 & 0 & 0 & 0 & 0 \\
\hline \multicolumn{38}{|c|}{ Group $T_{p}$} \\
\hline 1 & 0 & 0 & 4 & 5 & 7 & 8 & 12 & 12 & 13 & 13 & 12 & 9 & 9 & 8 & 8 & 8 & 8 & 8 & 7 & 0 & 0 & 0 & 0 & 0 & 0 & 0 & 0 & 0 & 0 & 0 & 0 & 0 & 0 & 0 & 0 & 0 & 0 \\
\hline 4 & 0 & 0 & 5 & 7 & 7 & 8 & 9 & 9 & 9 & 9 & 9 & 9 & 9 & 9 & 7 & 7 & 7 & 7 & 6 & 0 & 0 & 0 & 0 & 0 & 0 & 0 & 0 & 0 & 0 & 0 & 0 & 0 & 0 & 0 & 0 & 0 & 0 \\
\hline 15 & 0 & 4 & 4 & 7 & 8 & 11 & 12 & 12 & 12 & 13 & 10 & 10 & 10 & 10 & 7 & 7 & 7 & 7 & 6 & 0 & 0 & 0 & 0 & 0 & 0 & 0 & 0 & 0 & 0 & 0 & 0 & 0 & 0 & 0 & 0 & 0 & 0 \\
\hline 16 & 0 & 0 & 4 & 5 & 7 & 8 & 12 & 13 & 14 & 15 & 14 & 11 & 11 & 9 & 9 & 9 & 9 & 8 & 7 & 0 & 0 & 0 & 0 & 0 & 0 & 0 & 0 & 0 & 0 & 0 & 0 & 0 & 0 & 0 & 0 & 0 & 0 \\
\hline
\end{tabular}

\subsection{Efficacy of GCV as a Therapeutic Treatment (TGCV)}

No reduction in the number of days with clinical signs was observed in the $\mathrm{T}_{\mathrm{GCV}}$ group (GLMM, $P=.5$ ). The day corresponding to the peak of clinical severity was significantly different in this group (7.25) compared with group C (10), but not significantly different from group $\mathrm{T}_{\mathrm{P}}(8)$.

More remarkable was the result obtained in the $\mathrm{T}_{\mathrm{GCV}}$ group for virus shedding in terms of the duration, which showed a significant reduction to 9 days, compared with the control (18.25 days) and placebo (15.25 days) groups.

No significant differences were detected in the peak of the virus shedding between groups (Kruskal-Wallis, $P=.4$ ). However, all groups developed a peak between 9 and $11 \mathrm{dpi}$, except for the $\mathrm{T}_{\mathrm{GCV}}$ group, which developed a peak at 3.5 dpi (GLMM LSD FisherBonferroni, $P=.008$ ). In biological terms, the GCV treatment applied twice daily because $6 \mathrm{dpi}$ in mares showing clinical signs of $\mathrm{ECE}\left(\mathrm{T}_{\mathrm{GCV}}\right)$ reduced virus replication, preventing the development of a peak of virus shedding by $10 \mathrm{dpi}$, thus helping to clear the infection, and also clinically reducing the day of peak score.

Regarding the detection of infectious virus, mares from group $\mathrm{T}_{\mathrm{GCV}}$ cleared the infection earlier than those from the other treated $\left(\mathrm{P}_{4}\right.$ and $\mathrm{P}_{4 / 24}$ ) and nontreated groups ( $\mathrm{C}$ and $\mathrm{T}_{\mathrm{P}}$ ). The reduced number of animals per group did not allow a statistical analysis (Table 3).

\subsection{Neutralizing Antibody Response}

The kinetics of the neutralizing antibody response to EHV-3 infection was evaluated in all mares at $0,7,14,21,28$, and 36 dpi (Fig. 2). The statistical analysis considering the treatment group and time as the main fixed factors and the mares as a random factor and modeling the autoregressive effect of repeated measures on the same animal gave significant differences between groups $(P<$ $.0001)$ and times $(P<.0001)$, whereas the group*time interaction was not significant $(P=.2)$. These results are in agreement with the fact that the kinetics of neutralizing antibody responses in all groups was similar. At $7 \mathrm{dpi}$, groups $\mathrm{C}$ and $\mathrm{P}_{4}$ showed a significant increase in neutralizing antibody titers ( 1.15 and $1.2 \log _{10}$ reciprocal of serum dilution, respectively) when compared with $\mathrm{P}_{4 / 24}$, in which only one out of four mares seroconverted with a low titer (0.9). Regarding groups $\mathrm{T}_{\mathrm{GCV}}$ and $\mathrm{T}_{\mathrm{P}}$, both showed an antibody response similar to that of the untreated control group ( $\mathrm{T}_{\mathrm{GCV}}$ : 1.01 ; $T_{p}: 1.31$ ). The peak of antibody titers was observed at $14 \mathrm{dpi}$ for all the groups and remained between 2.71 and 2.33 until the end of the study.

\section{Discussion}

This experimental trial was conducted as a pilot study to obtain preliminary data on the topical treatment of mares infected with EHV-3 with GCV by analyzing one concentration of the drug applied following different regimens. The results obtained showed that a therapeutic topical application of GCV in the genital area of mares experimentally infected with EHV-3 could be beneficial in the clinical outcome of ECE, reducing the duration of virus shedding and consequently diminishing the risk of contagion and environmental contamination. No adverse effects were observed in the mares treated with GCV during the experimental study.

When used as a preventive treatment, GCV was applied shortly after the experimental infection and before the appearance of genital ECE lesions to mimic the situation of subclinically infected mares at the moment of the clinical inspection before mating. These groups ( $\mathrm{P}_{4}$ and $\mathrm{P}_{4 / 24}$ ) showed no significant differences in the severity of the disease, virus shedding, or infectious virus detected after treatment.

Although other studies in goats infected with caprine alphaherpesvirus 1 preventively treated with cidofovir showed that frequent applications for 10 days drastically decreased viral excretion and clinical scores [20], in equine reproductive centers, this kind of therapy could be difficult to carry out by the veterinarians, as, in practice, mares will probably not be treated for more than 2 days before mating (personal communication).

Our results showed that a GCV therapeutic treatment in mares presenting ECE caused a significant reduction in the duration of viral excretion, preventing the development of the peak day of virus shedding between 9 and $11 \mathrm{dpi}$ as recorded in the other groups. The results also showed that the magnitude of the lesions in these animals, as measured by the clinical score compared with untreated controls, was also reduced, although not significantly. When analyzing the excretion of infectious virus at $12 \mathrm{dpi}$, all the mares in group $\mathrm{T}_{\mathrm{GCV}}$ (treated twice daily for 13 days initiating on 6 dpi) were negative for EHV-3, compared with the control, placebo, and preventive groups, which were all positive. It may be expected 
A

\begin{tabular}{|c|c|c|c|c|c|c|}
\hline \multirow[b]{2}{*}{ Mares } & \multirow[b]{2}{*}{$\mathbf{0}$} & \multicolumn{5}{|c|}{ Days post-infection } \\
\hline & & 7 & 14 & 21 & 28 & 36 \\
\hline \multicolumn{7}{|l|}{ Group C } \\
\hline 3 & 0 & 1.2 & 2.7 & 2.7 & 2.7 & 2.4 \\
\hline 9 & 0 & 0.9 & 2.7 & 2.7 & 2.4 & 2.4 \\
\hline 14 & 0 & 1.2 & 2.7 & 2.7 & 2.7 & 2.4 \\
\hline 18 & 0 & 1.2 & 2.7 & 2.7 & 2.7 & 2.1 \\
\hline Mean & $0 \mathrm{~A}$ & $1.1 C^{*}$ & $27 \mathrm{D}$ & 2.7D & $2.6 \mathrm{D}$ & $2.3 D$ \\
\hline s.d & 0 & 0.2 & 0 & 0 & 0.2 & 0.2 \\
\hline \multicolumn{7}{|l|}{ Group $P_{4}$} \\
\hline 2 & 0 & 1.2 & 2.7 & 2.7 & 2.4 & 2.4 \\
\hline 10 & 0 & 1.5 & 2.4 & 2.4 & 2.4 & 2.1 \\
\hline 11 & 0 & 0.9 & 2.7 & 2.7 & 2.7 & 2.1 \\
\hline 20 & 0 & 0.9 & 2.7 & 2.7 & 2.7 & 2.7 \\
\hline Mean & $0 \mathrm{~A}$ & $1.1 C^{*}$ & 2.60 & $2.6 \mathrm{D}$ & $2.6 \mathrm{D}$ & $2.3 \mathrm{D}$ \\
\hline s.d & 0 & 0.3 & 0.2 & 0.2 & 0.2 & 0.3 \\
\hline \multicolumn{7}{|c|}{ Group $P_{424}$} \\
\hline 6 & 0 & 0 & 2.7 & 2.4 & 2.4 & 2.4 \\
\hline 8 & 0 & 0.9 & 2.7 & 2.4 & 2.4 & 2.4 \\
\hline 17 & 0 & 0 & 2.7 & 2.1 & 2.1 & 2.1 \\
\hline 19 & 0 & 0 & 2.4 & 2.4 & 2.4 & 2.4 \\
\hline Mean & OA & $0.2 \mathrm{AB}$ & 2. & 2.3D & $2.3 \mathrm{D}$ & $2.3 \mathrm{D}$ \\
\hline s.d & 0 & 0.5 & & 0.2 & 0.2 & 0.2 \\
\hline \multicolumn{7}{|c|}{ Group $T_{\text {GCV }}$} \\
\hline 5 & 0 & 1.2 & 2.4 & 2.4 & 2.4 & 2.1 \\
\hline 7 & 0 & 1. & & .4 & .4 & 2.4 \\
\hline 12 & 0 & 0.9 & 2.7 & 2.7 & 2.7 & 2.7 \\
\hline 13 & 0 & 0 & 2.7 & 2.4 & 2.4 & 2.1 \\
\hline Mean & $0 A$ & $0.8 B C$ & 260 & 2.5D & 2.5D & $2.3 D$ \\
\hline s.d & 0 & 0.6 & 0.2 & 0.2 & 0.2 & 0.3 \\
\hline \multicolumn{7}{|l|}{ Group $T_{P}$} \\
\hline 1 & 0 & 1.5 & 2.7 & 2.7 & 2.7 & 2.7 \\
\hline 4 & 0 & 1.5 & 2.7 & 2.4 & 2.4 & 2.4 \\
\hline 15 & 0 & 1.2 & 2.4 & 2.1 & 2.1 & 2.1 \\
\hline 16 & 0 & 0 & 2.7 & 2.7 & 2.7 & 2.4 \\
\hline Mean & $0 A$ & $1.1 C^{*}$ & 2.6 & $2.5 \mathrm{D}$ & $2.5 \mathrm{D}$ & $2.4 \mathrm{D}$ \\
\hline s.d & 0 & 0.7 & 0.2 & 0.3 & 0.3 & 0.2 \\
\hline
\end{tabular}

B

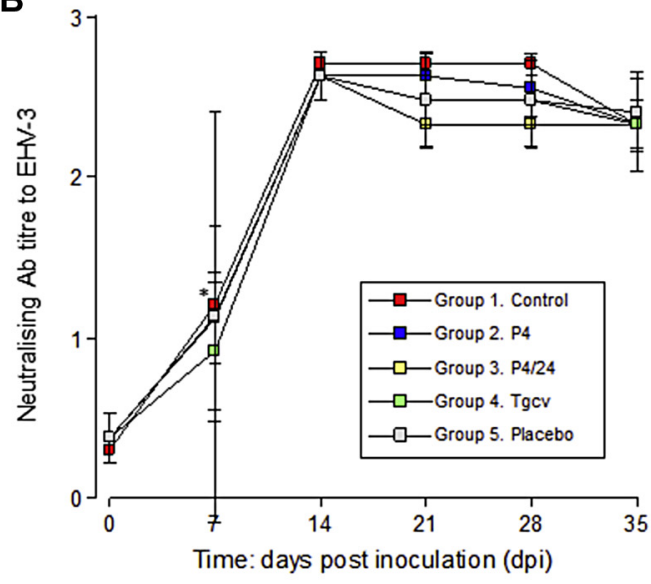

Means in the same column (days) with different letters differ significantly (GLMM: ptreatment<0.0001; ptime<0.0001; pinteraction $=0.2$ )

Fig. 2. Neutralizing antibody response in mares experimentally infected with EHV-3: (A) - raw data and (B) - kinetics of neutralizing antibody.

that more advantageous results could be obtained if the GCV therapeutic treatment is started sooner, as proposed by other authors. It is claimed that the sooner that an antiviral drug is administered after infection, the higher the efficacy achieved regarding the progressive evolution of clinical signs [18]. Moreover, the selection of the concentration for this pilot study was based on previous in vitro studies [14], but further studies should be carried out to determine whether higher doses, between 0.1 and $1 \%$, as proposed by other authors for antiviral treatment against alphaherpesviruses $[15,18]$, could improve the performance of GCV to inhibit EHV-3 replication in vivo. Accordingly, it will also be interesting to assess the use of GCV in association with other antiviral compounds, mainly those with a different mechanism of action, which could enhance the efficacy of the treatment. These synergistic compounds can contribute to the inhibition of infection/ replication by specific neutralization with antibodies against EHV-3 or by the immunomodulation of the immune system [21]. Specific antibodies against EHV-3 could have a neutralizing activity on the virus before the infection of epithelial cells and can be produced in camelids (nanoantibodies) [22] or chicken (IgY) [23]. In this way, the activity of neutralizing antibodies can be synergistic to the activity of GCV, reducing the amount of drug needed and consequently the economic cost of the treatment. Although this has not yet been tested in vitro or in vivo against EHV-3, a project is being proposed at our laboratory to improve this type of treatment.

Finally, the study of the statistical power showed that only three of the variables analyzed reached a power higher than $80 \%$ (peak day of the score, duration of virus shedding, and peak day of virus shedding). For the rest of the variables analyzed, this pilot study allowed us to estimate that the number of animals required to reach the desired power should be between 5 and 10 as to confirm the treatment efficacy. Then, these results will be used for a next field trial using GCV in combination with a synergistic compound.

The duration of the clinical lesions in the placebo group was as long as that in the group treated with GCV. Therefore, contrary to that found in another report [20], this suggests that the cream by itself could have some effect on the healing of EHV-3-induced lesions. However, we should consider that both treatments started at $6 \mathrm{dpi}$, very close to the high clinical score day of both groups when the pathogenesis of lesions was in an advanced stage.

The results obtained in this study in mares 5 and 15 (groups $\mathrm{T}_{\mathrm{GCV}}$ and $T_{P}$, respectively) also suggest that asymptomatic virus excretion with high circulating antibody titers can occur $[2,17]$ and that these circulating antibodies could collaborate to the reduction of clinical disease [16]. This asymptomatic virus excretion could be due to reactivation or reinfection through contact among mares located in the same paddock.

Based on the current results, we can conclude that GCV demonstrated an antiviral activity on EHV-3 replication when administered topically for the treatment of genital lesions induced by EHV-3 in mares. The use of GCV as a therapeutic treatment in clinically affected animals could be beneficial in the clinical outcome of ECE mostly in stallions, reducing the duration of virus shedding, and consequently diminishing the time of healing. The application of this protocol in mares and stallions affected would reduce the risk of contagion and environmental contamination. As 
the administration of the treatment does not require any expertise, owners or breeders can easily do it, which would be helpful for treatments during the breeding season. Further studies increasing the GCV concentration and/or improving the dosing regimen should be carried out to optimize the therapeutic protocol. Moreover, the addition of other compounds (IgY, nanoantibodies) could also optimize the protocol and should be further evaluated.

\section{Acknowledgments}

The authors are very grateful to Dr. Celina Vega from "Instituto Nacional de Tecnología Agropecuaria" for her careful reading of the manuscript, to Silvia Tordoya and Luciana Becerra, also from "Instituto Nacional de Tecnología Agropecuaria", for their technical support in the laboratory, to Diego Franco and Claudio Fioroni from "Instituto Nacional de Tecnología Agropecuaria", and to Nelson Román, Guillermo Ruesga, Ariel Ibarra, Dardo Rodrigo Jimenez, Andrés Verón, Pablo García, and Santiago Moar from "Laboratorio de Remonta y Veterinaria, Ejército Argentino", for the care of the mares and their assistance on daily sampling.

Financial disclosure

This research was supported by INTA and the INTA HARAS agreement.

\section{References}

[1] Barrandeguy M, Thiry E. Equine coital exanthema and its potential economic implications for the equine industry. Vet J 2012;191:35-40.

[2] Barrandeguy M, Perkins J, Mac Donough J, Vissani A, Olguin C, Thiry E. Occurrence of equine coital exanthema in mares from an embryo transfer center. J Equine Vet Sci 2010;30:145-9.

[3] Negussie H, Li Y, Tessema TS, Nauwynck HJ. Replication characteristics of equine herpesvirus 1 and equine herpesvirus 3 : comparative analysis using ex vivo tissue cultures. Vet Res 2016:1-11.

[4] Allen G, Umphenour W. Equine coital exanthema. In: Coetzer J, Tustin R, editors. Equine coital exanthema. Infect. Dis. Livestock. Cape Town: Oxford Press; 2004. p. 860-7.

[5] Pascoe R. The effect of equine coital exanthema on the fertility of mares covered by stallions exhibiting the clinical disease. Aust Vet J 1981;57:111-4.

[6] Aurich C. Reproductive cycles of horses. Anim Reprod Sci 2011;124:220-8.

[7] Squires E. Changes in equine reproduction: have they been good or bad for the horse industry? J Equine Vet Sci 2009;29:268-73.
[8] Barrandeguy M, Vissani A, Pont Lezica F, Salamone J, Heguy A, Becerra L, et al. Subclinical infection and periodic shedding of equid herpesvirus 3. Theriogenology 2010;74:576-80.

[9] Vissani MA, Tordoya MS, Tsai Y, Lee PA, Shen Y, Lee F, et al. On-site detection of equid alphaherpesvirus 3 in perineal and genital swabs of mares and stallions. Virol Methods 2018;257:29-32.

[10] Vissani A, Thiry E, Dal Pozzo F, Barrandeguy M. Antiviral agents against equid alphaherpesviruses: current status and perspectives. Vet J 2016;207:38-44.

[11] Toishi Y, Tsunoda N, Kirisawa R. Occurrence of equine coital exanthema (ECE) in stallions in Japan and effectiveness of treatment with valacyclovir for ECE. J Vet Med Sci 2017;79:632-5.

[12] Cullinane A, McGing B, Naughton C. The use of acyclovir in the treatment of coital exanthema and ocular disease caused by equine herpesvirus 3 . e. In: Plowright W, Nakajima H, editors. Equine Infect. Dis. VII. Newmarket (Suffolk): R \& W Publications; 1994. p. 55.

[13] Smith KO, Galloway KS, Hodges SL, Ogilvie KK, Radatus BK, Kalter SS, et al. Sensitivity of equine herpesviruses 1 and 3 in vitro to a new nucleoside analogue, 9-[[2-hydroxy-1-(hydroxymethyl) ethoxy] methyl] guanine. Am J Vet Res 1983;44:1032-5.

[14] Vissani M, Zabal O, Tordoya M, Parreño V, Thiry E, Barrandeguy M. In vitro comparison of acyclovir, ganciclovir and cidofovir against equid alphaherpesvirus 3 and evaluation of their efficacy against six field isolates. Rev Argent Microbiol 2018:50:380-90.

[15] Colin J. Ganciclovir ophthalmic gel , 0 . $15 \%$ : a valuable tool for treating ocular herpes. Clin Ophtalmol 2007;1:441-53.

[16] Barrandeguy M, Vissani A, Olguin C, Barbara G, Valenzuela H, Becerra L, et al. Experimental infection with equid herpesvirus 3 in seronegative and seropositive mares. Vet Microbiol 2012;160:319-26.

[17] Barrandeguy M, Vissani A, Olguin C, Becerra L, Miño S, Pereda A, et al, Experimental reactivation of equine herpesvirus-3 following corticosteroid treatment. Equine Vet J 2008;40:593-5.

[18] Tempesta M, Crescenzo G, Camero M, Bellacicco AL, Tarsitano E, Decaro N, et al. Assessing the efficacy of cidofovir against herpesvirus-induced genital lesions in goats using different therapeutic regimens. Antimicrobial Agents Chemother 2008;52:4064-8.

[19] Cohen Jacob. Statystical power analysis for the behavioral sciences. Second ed. New York, USA: Lawrence Erlbaum Associates; 1988.

[20] Tempesta M, Camero M, Bellacicco AL, Tarsitano E, Crescenzo G. Potent inhibition of genital herpesvirus infection in goats by cidofovir. Antivir Ther 2007; 12:977-9.

[21] Camero M, Buonavoglia D, Lucente M, Losurdo M, Crescenzo G, Trerotoli P, et al. Enhancement of the antiviral activity against caprine herpesvirus type 1 of Acyclovir in association with Mizoribine. Res Vet Sci 2017;111:120-3.

[22] Vega C, Bok M, Vlasova A, Chattha K, Gómez-Sebastián S, Nuñez C, et al. Recombinant monovalent llama-derived antibody fragments (VHH) to rotavirus VP6 protect neonatal gnotobiotic piglets against human rotavirus-induced diarrhea. PLoS Pathog 2013;9:1-17.

[23] Vega C, Bok M, Chacana P, Saif L, Fernandez F, Parreño V. Egg Yolk IgY: protection against Rotavirus induced Diarrhea and Modulatory effect on the systemic and mucosal antibody responses in newborn calves. Vet Immunol Immunopathol 2012;142:156-69. 